\title{
Role and Side Effects of Topical Phenytoin Dressing in Diabetic Foot Ulcer as Compared to Conventional Betadine Dressing
}

\author{
Authors \\ *Dr Shrirang Yadwadkar ${ }^{1}$, Dr.Mrs.Thipse ${ }^{2}$, Dr Sudhir Mutha ${ }^{3}$, Dr Niranjan Dash ${ }^{4}$ \\ Dr Atul Khalkar ${ }^{5}$, Dr Jayant Gadekar ${ }^{6}$ \\ ${ }^{1}$ Resident, Dept of Surgery, ${ }^{2}$ Professor, Dept of Surgery, ${ }^{3}$ Associate Professor, Dept of Surgery, \\ ${ }^{4,5}$ Professor, Dept of surgery ${ }^{6}$ Professor and Head of Department Dept of Surgery,
}

Padmashree Dr. Vithalrao Vikhe Patil Medical College \& Hospital, Near Govt. Milk Dairy, Vilad Ghat,

Ahmednagar, Maharashtra

Corresponding Author

Dr Shrirang Yadwadkar

Email: yadwadkarshrirang@gmail.com,*Phone No:08855022933

* Address - Dept. Of Surgery, PDVVPF'S Medical College and Hospital, Vilad Ghat, Ahmednagar, India. Pin- 414111

\begin{abstract}
Diabetic ulcer is the most frequent reason for hospitalization in patients with diabetes. It has increased the cost of treatment and hospitalization of these patients.

Currently a lot of attention is being placed on the development of expensive topical growth factors for wound healing. Thus there remains a quest for better wound healing agents. One such agent is phenytoin which is cheap, easy to use and readily available for medical practice. Phenytoin (diphenylhydantoin) was initially introduced into therapy for the effective control of convulsive disorders. A common side effect with systemic phenytoin treatment is the development of fibrous overgrowth of gingiva. This apparent stimulatory effect of phenytoin on connective tissue suggested an encouraging possibility for its use in wound healing. In this study, the wound-healing efficacy of phenytoin was investigated as compared to the conventional betadine dressings. Keywords: topical phenytoin, diabetic foot ulcer, betadine, wound healing, granulation, epithelisation
\end{abstract}

\section{Introduction}

Diabetic ulcer is the most common reason for hospitalization in patients with diabetes. It has increased the cost of treatment and hospitalization of patients ${ }^{(1)}$.

Slow healing wounds represent a major health burden and drain on resources, contributing to substantial disability, morbidity, and costs. Currently a lot of attention is being placed on the development of expensive topical growth factors for wound healing ${ }^{(2)}$. Thus there remains a quest for better wound healing agents. One such agent is phenytoin which is cheap, easy to use and readily available for medical practice. Phenytoin (diphenylhydantoin) was initially introduced into therapy for the effective control of convulsive disorders, anti arrthymic and psychomotor epilepsy. It can be used to treat some other conditions like 
epidermolysis bullosa, inflammatory conditions A common side effect with phenytoin treatment is the development of fibrous overgrowth of gingiva ${ }^{(3)}$ This apparent stimulatory effect of phenytoin on connective tissue suggested an encouraging possibility for its use in wound healing. The beneficial effect of phenytoin in wound healing had been reported in 1945 and was observed in the first clinical trial for gingival wounds in 1958 by Shapiro ${ }^{(4)}$. Since wound healing is complicated process with incorporation of different mechanisms, the exact mechanism by which phenytoin works in wound healing is not exactly understood but possible mechanisms are-

- Stimulation of fibroblast proliferation

- Enhancing formation of granulation tissue

- Decreasing collagenase activity and inhibition of glucocorticoid activity

- Neovascularization

- Promotion of growth of connective tissue. ${ }^{(5)}$

In this study we will study the role and side effects of topical phenytoin application over non healing wound than conventional betadine dressings.

Study Type- The study type of the research project will be prospective \& comparative type.

\section{Aims And Objectives-}

To compare the efficacy of topical phenytoin with conventional betadine wound dressings in healing of diabetic foot ulcers, in terms of:

- $\quad$ No of days required for healing

- Rate of granulation tissue formation

- $\quad$ Quality of graft bed and skin graft up take if skin grafting done for the wound.

- $\quad$ Side effects of topical phenytoin dressing.

\section{Methodology:}

- This prospective comparative study will include 50 patients with diabetic foot ulcers admitted in PDVVPF"s hospital satisfying all inclusive criteria after clearance from ethical committee.The whole sample population with diabetic foot with diabetes under control by either oral hypoglycaemics or on insulin $(n=50)$ is divided into two equal and comparable groups based on willingness for undergoing topical phenytoin therapy for the wound. Those who were not willing were subjected to conventional wound care forming the control group.

- Selection of patients was done by random sampling method. All patients underwent general physical and clinical examination for peripheral vascular status and peripheral neuropathic changes in lower extremities. Routine hematological, biochemical, urine microscopic investigations were done for each patient.The standard antibiotics were given according culture sensitivity suspectibility. The wounds were thoroughly debrided when necessary. After slough removal, the surface area was measured, tracing the outline on butter paper.

- A sterile guage soaked in a suspension of $100 \mathrm{mg}(1 \mathrm{ml})$ phenytoin capsule in $10 \mathrm{ml}$ normal saline $(10 \mathrm{mg} / \mathrm{cm} 2$ TBSA) is placed over the wound. The control group dressing is done with $5 \% \mathrm{w} / \mathrm{v}$ povidone-iodine solution. Twice daily dressings are done for 10days for both the groups. observed and spontaneously reported (local and systemic side effects of phenytoin were documented. If required patient are posted for skin grafting and wound is assessed on $5^{\text {th }}$ postoperative day for graft uptake and no. of days of hospitalization are noted. Follow up of the patient was done after 1 month after 
discharge to assess wound dimentions and any complications after skin grafting. The results obtained were statistically evaluated and the main parameters which were analysed were

- rate of granulation tissue formation as percentage of ulcer surface area

- graft survival and take up

- Duration of hospital stay.

The variables were compared using Paired and Unpaired Student's t-test and P value of $<0.05$ was considered significant.

\section{Selection of cases-}

\section{INCLUSION CRITERIA:}

1. Wound more than 14 days

2. Any age, sex

3. Control of diabetes mellitus under control on oral hypoglycemic or on insulin.

4. grade I and II foot ulcers according to Meggitt-Wagner clinical classification

\section{EXCLUSION CRITERIA}

1. Patients with malignant ulcers, ischemic ulcers and osteomyelitis

2. Patients with malnutrition

3. Patients on corticosteroids, immunosuppressant and chemotherapy, or ulcer due to other etiologies.

4. Patients with fistulas to organs or body cavities

5. grade III,IV,V foot ulcers according to Meggitt-Wagner clinical classification

6. persons allergic to phenytoin.

\section{OBSERVATION AND RESULTS}

The 100 patients admitted for the study were divided into two equal and comparable groups. Patients subjected to topical phenytoin dressings were classified under study and those who underwent conventional betadine wound dressing were classified as control.

Table 1: Sex wise distribution of patients

\begin{tabular}{|r|c|c|c|}
\hline Sex & Betadine & Phenytoin & Total \\
\hline $\mathbf{F}$ & 14 & 7 & 21 \\
\hline $\mathbf{M}$ & $\mathbf{3 8}$ & 41 & 79 \\
\hline Total & $\mathbf{5 0}$ & $\mathbf{5 0}$ & $\mathbf{1 0 0}$ \\
\hline
\end{tabular}

All patients belonged to middle and low socio economic groups. There were 41 males and 7 females in the study group and 38 males and 14 females in the control group. 


\section{JMSCR Vol||3||Issue||12||Page 8781-8788||December}

Table 2: Age wise distribution of patients

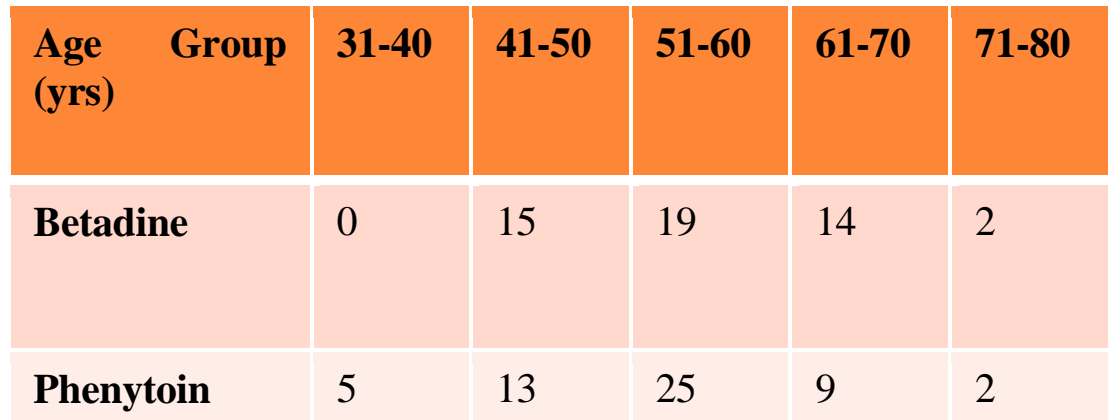

The age wise distribution of patients in this study is as shown above. The mean age in study group was $52.94 \mathrm{yrs}$ and mean age in control group was 54.82yrs.

Table 3: Mean ulcer surface area in both the groups

\begin{tabular}{|l|l|l|l|l|l|l|}
\hline Group & N & Mean & $\begin{array}{l}\text { Standard } \\
\text { deviation }\end{array}$ & Median & $\begin{array}{l}\mathbf{t} \\
\text { value }\end{array}$ & $\begin{array}{l}\mathbf{p} \\
\text { value }\end{array}$ \\
\hline Betadine & 50 & 37.509 & 7.228 & 38.51 & 2.248 & $\mathbf{0 . 0 1 4}$ \\
\hline Phenytoin & $\mathbf{5 0}$ & 39.407 & 2.841 & 39.22 & \\
\hline Total & 100 & 38.98 & 5.642 & 39.71 & & \\
\hline
\end{tabular}

The mean ulcer surface area in control group is $37.5 \mathrm{~cm}^{2}$ and in the study group is $39.4 \mathrm{~cm}^{2}$. The ulcer surface area is measured twice using butter paper. The efficacy of the dressing was assessed as percentage of ulcer surface area covered by healthy granulation tissue after 14 days.

Table 4: Rate of Granulation tissue formation as percentage of ulcer surface area

\begin{tabular}{|l|l|l|l|l|l|l|}
\hline Group & N & Mean & $\begin{array}{l}\text { Standard } \\
\text { deviation }\end{array}$ & Median & t value & p value \\
\hline Betadine & 50 & 36.171 & 5.216 & 37.06 & 3.796 & 0.003 \\
\hline Phenytoin & 50 & 39.548 & 2.575 & 39.65 & \\
\hline Total & 100 & 37.755 & 4.688 & 38.98 & & \\
\hline
\end{tabular}

The mean rate of granulation tissue formation in study group is $97.93 \mathrm{~cm}^{2} \pm 4.7$ (SD) of total ulcer surface area and in control group is $97.07 \mathrm{~cm}^{2} \pm 2.4(\mathrm{SD})$ of total ulcer surface area. 


\section{JMSCR Vol||3||Issue||12||Page 8781-8788||December}

Table 5: Graft take up as percentage of ulcer surface area

\begin{tabular}{|l|l|l|l|l|l|l|}
\hline Group & N & Mean & $\begin{array}{l}\text { Standard } \\
\text { deviation }\end{array}$ & Median & t value & p value \\
\hline Betadine & 50 & 37.102 & 5.457 & 37.5 & 3.876 & 0.001 \\
\hline Phenytoin & 50 & 39.945 & 2.680 & 39.60 & \\
\hline Total & 100 & 38.450 & 4.234 & 39.35 & \\
\hline
\end{tabular}

The patients in both groups were subjected to split thickness skin grafting as the final treatment modality. The graft take up was then assessed at the end of the 5th post operative day as the percentage of ulcer surface area is given above.

The mean graft take up in the study group is $98.93 \% \pm 3.6(\mathrm{SD})$ and in the control group is $96.91 \% \pm 4.5(\mathrm{SD})$

The main post operative parameters noted in both the groups during follow up were:

-wound size

-contracture of graft

-pain

-infection.

All these parameters were less in study as compared to control

Table 6: Duration of hospital stay

\begin{tabular}{|l|l|l|l|l|l|l|}
\hline Group & N & Mean & $\begin{array}{l}\text { Standard } \\
\text { deviation }\end{array}$ & Median & $\begin{array}{l}\mathbf{t} \\
\text { value }\end{array}$ & $\begin{array}{c}\mathbf{p} \\
\text { value }\end{array}$ \\
\hline Betadine & 50 & 33.20 & 3.20 & 33.30 & 4.292 & 0.003 \\
\hline Phenytoin & 50 & 26.48 & 3.213 & 26.40 & \\
\hline Total & 100 & 30.29 & 3.234 & 29.50 & & \\
\hline
\end{tabular}

The quality of life of the patient in both the groups was assessed by the assessment of total hospital stay as number of days of admission in the hospital.

The mean hospital stay in control group was $33.2 \pm 3.2$ (SD) days and that in the study group was $26.48 \pm 3.2$ (SD) days.

$\mathrm{P}$ value is $<0.0005$ which is significant

5 patients developed burning sensations after application of phenytoin.

2 patients out of 50 had cutaneous pustulous eruptions

No other significant side effects were noted 


\section{Analysis}

Both groups had comparable age and sex distribution as seen in above depicted graphs.

The mean rate of granulation tissue formation in study group is $97.93 \mathrm{~cm}^{2}$ of total ulcer surface area and in control group is $97.07 \mathrm{~cm}^{2}$. The results were analysed by unpaired student t-test which showed significant difference in rate of granulation tissue formation $(\mathrm{p}<0.0005)$.

The mean graft take up in the study group is $98.93 \mathrm{~cm}^{2}$ and in the control group is $96.91 \mathrm{~cm}$. The results were analysed by unpaired student t-test which showed highly significant difference in graft take up ( $p$ of $0.001)$.

The total number of days of hospital stay for the patient was also compared. The mean number of days of hospital stay in control group was 33.2days and that in the study group was 26.48 days. The results were analysed by unpaired student t-test which showed significant difference in the number of days of hospital stay $(\mathrm{p}<0.0003)$.

\section{Discussion}

This study was done as a prospective randomized controlled comparative study to compare the efficacy of topical phenytoin moist dressing to conventional moist wound dressing in the management of diabetic ulcer. Mean age group in Muthu kumaraswamy et al (7) study in study group is 56.4 yrs and in the control group is $58.7 \mathrm{yr}$ while in the present study it is $52.94 \mathrm{yrs}$ in study group and 54.82yrs in control group.

The mean rate of granulation tissue formation in Muthu kumaraswamy et al study in study group was $74 \%$ and in control group was $53.3 \%$. The mean rate of granulation tissue formation in study group is $97.93 \mathrm{~cm}^{2}$ of total ulcer surface area and in control group is $97.07 \mathrm{~cm}^{2}{ }^{(7)}$. Study done by Banal TK et al ${ }^{(8)}$ agrees with the same that the phenytoin promotes the granulation tissue formation The percentage of graft take up in Muthu kumaraswamy et al study in the study group is $72.4 \%$ and in the control group is $58.4 \%$ while the percentage of graft take up in the study group is $98.93 \%$ and in the control group is $96.91 \%$.our study shows that phenytoin also promotes graft take up which agrees with te studies done by Lodha SC et al ${ }^{(9)}$ and Anstead $\mathrm{GH}$ et al ${ }^{(10) .}$

The duration of hospital stay in Muthu kumaraswamy et al study in control group was 45days and that in the study group was 21 days while in the present study the mean hospital stay in control group was 33.2days and that in the study group was 26.48 days. This shows that phenytoin use reduces the hospital stay and morbidity which agrees with the study of Kumar S et al. ${ }^{(11)}$

\section{Figure 1:}

Ulcer before Phenytoin Dressing

Ulcer After Phenytoin Dressing
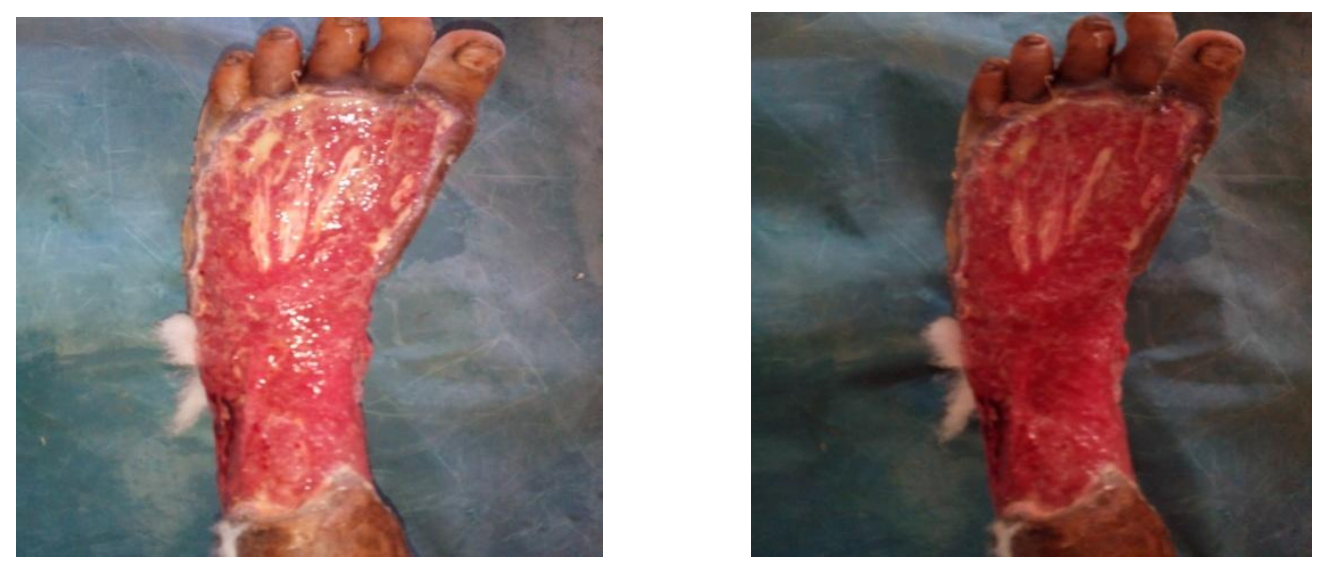
Figure 2:

Ulcer before Phenytoin Dressing

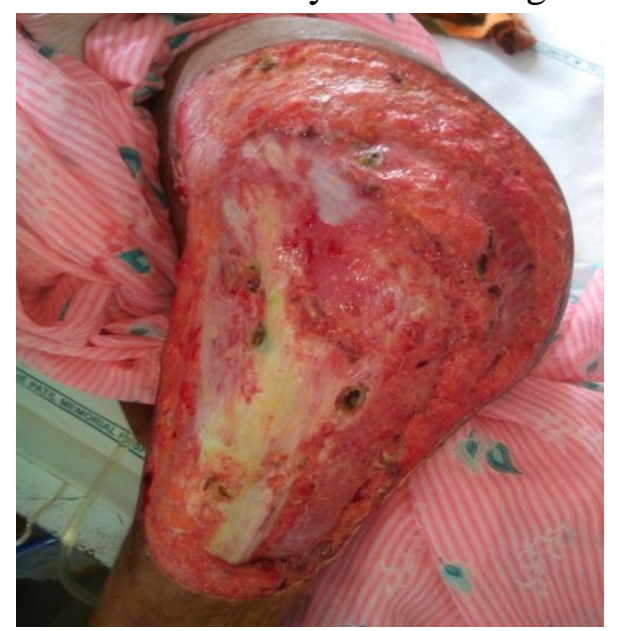

Ulcer After Phenytoin Dressing

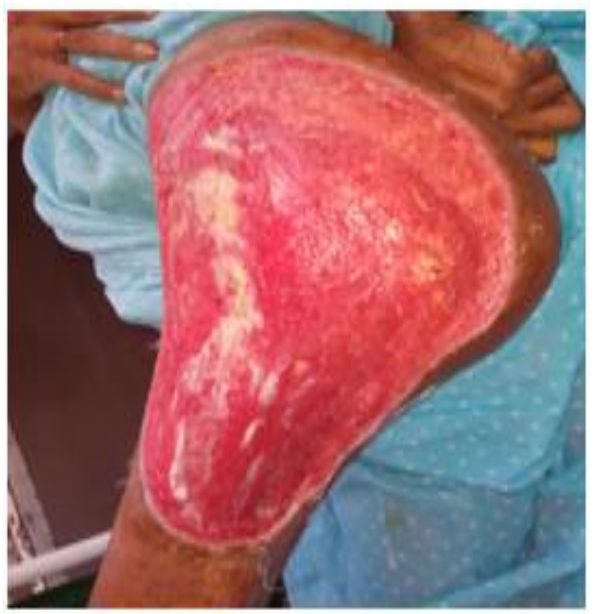

\section{Limitations of the study}

The most important limitation of the present study is its sample size. A randomised controlled comparative study with a much larger population may help to furthur substantiate the findings or reveal variations which were not observed in the present study. The cost burden on the patient is also not analysed in this study as it can be influenced by various factors other than the cost of dressings. Phenytoin dressing was found to be less expensive compared to conventional moist dressing. However, no commercial preparation of phenytoin is available in the market so far.

The quantitative assessment of the post operative parameters like wound contracture, pain and residual raw ulcer area was also not included in the present study, which if included, might have given a much better analysis of the efficacy of topical phenytoin moist dressing as compared to conventional moist dressing.

\section{Summery}

$>$ Increased rate of granulation tissue formation was seen in topical phenytoin group when compared to conventional group.

$>$ Better graft take up was seen in topical phenytoin group when compared to conventional group.

$>$ Considerable effect on bacterial load was seen in topical phenytoin group when compared to conventional group.

$>$ Shorter duartion of hospital stay was seen in topical phenytoin group when compared to conventional group.

$>$ Topical phenytoin dressing thus is an effective, inexpensive and widely available therapeutic agent in wound healing.

$>$ Follow up observations revealed that topical phenytoin dressing group suffered

$>$ lesser post skin grafting complications like wound contracture, residual raw area and pain compared to conventional group.

\section{Conclusion}

In the present study it was concluded that topical phenytoin by decreasing bacterial load, forming healthy granulation tissue helps in better graft take up than the conventional dressing. Because of enhanced healing and overall hospital stay, the post operative complications were less in topical phenytoin dressing group. Thus topical phenytoin moist wound dressing can be considered as superior option in management of 
diabetic ulcers. But further studies with larger population will be needed in the future before topical phenytoin dressing can be added to the wide spectrum of treatment modalities available in the managemnt of diabetic ulcers and ulcers of other etiologies.

\section{References}

1. Steed DT, Donahoe D, Webster MW, Linsley L. Diabetic ulcer study Group : Effect of extensive debridement and treatment on the healing of diabetic foot ulcers. J Am Coll Surg 1996;183:61-4.

2. Clark RA. Basis of cutaneous wound repair. J Dermatol Surg Oncol. 1993;19:693-706. [PubMed: 8349909]

3. Anstead GM, Hart LM, Sunahara JF, Liter ME. Phenytoin in wound healing. Ann Pharmacother. 1996;30:768-75. [PubMed: 8826558]

4. Shapiro M. Acceleration of gingival wound healing in non-epileptic patients receiving diphenylhydantoin sodium. Exp Med Surg 1958;16:41-53

5. Talas G, Brown RA, McGrouther A. Role of phenytoin in Wound healing a wound pharmacology perspective Biochem Pharmacol 1999;57(10):1085-94.

6. Banal NK, Mukul. Comparison of topical phenytoin with normal saline in the treatment of chronic tropic ulcers in leprosy. IM J Dermatol 1993:32:210-3.

7. Muthukumaraswamy MG, Sivakumar G, Manoharan G. Topical phenytoin in diabetic loot ulcers. Diabetes Care 1991;14:909-11

8. Lodha SC, Lohiya ML, Vyas MCR, Bhandari S. Goyal RR, Harsh MK. Role of phenytoin in healing of large abscess cavities. BrJ Surg 1991;78:105-8.

9. Yadhav JK, Singhvi AM, Kumar N, Garg S. Topical phonytoin in the treatment of split thickness skin autograft donor sites: a comparative study with polyurethane membrane drape and conventional dressing. Bums 1993;19:306-10.

10. Anstead GH, Hart LM, Sunahara JF, Liter ME. Phenytoin in wound healing. Ann Pharmacother 1996:30:769-75.

11. Kumar S. Boulton AJM. Response to Topical pherrytoin in diabetic foot ulcers'. Diabetes Care 1992;15:1433-4

\section{Source of Support: Nil}

Conflict of Interest: None declared 